\title{
Participation and the Role of Neuropsychological Functioning in Myotonic Dystrophy Type 1
}

Citation for published version (APA):

Van Heugten, C., Meuleman, S., Hellebrekers, D., Kruitwagen-van Reenen, E., \& Visser-Meily, J. (2018). Participation and the Role of Neuropsychological Functioning in Myotonic Dystrophy Type 1. Journal of neuromuscular diseases, 5(2), 205-214. https://doi.org/10.3233/JND-170246

Document status and date:

Published: 29/05/2018

DOI:

10.3233/JND-170246

Document Version:

Publisher's PDF, also known as Version of record

Document license:

Taverne

Please check the document version of this publication:

- A submitted manuscript is the version of the article upon submission and before peer-review. There can be important differences between the submitted version and the official published version of record.

People interested in the research are advised to contact the author for the final version of the publication, or visit the DOI to the publisher's website.

- The final author version and the galley proof are versions of the publication after peer review.

- The final published version features the final layout of the paper including the volume, issue and page numbers.

Link to publication

\footnotetext{
General rights rights.

- You may freely distribute the URL identifying the publication in the public portal. please follow below link for the End User Agreement:

www.umlib.nl/taverne-license

Take down policy

If you believe that this document breaches copyright please contact us at:

repository@maastrichtuniversity.nl

providing details and we will investigate your claim.
}

Copyright and moral rights for the publications made accessible in the public portal are retained by the authors and/or other copyright owners and it is a condition of accessing publications that users recognise and abide by the legal requirements associated with these

- Users may download and print one copy of any publication from the public portal for the purpose of private study or research.

- You may not further distribute the material or use it for any profit-making activity or commercial gain

If the publication is distributed under the terms of Article $25 \mathrm{fa}$ of the Dutch Copyright Act, indicated by the "Taverne" license above, 


\title{
Research Report
}

\section{Participation and the Role of Neuropsychological Functioning in Myotonic Dystrophy Type 1}

\author{
Caroline Van Heugten ${ }^{\mathrm{a}, \mathrm{d}}$, Susan Meuleman ${ }^{\mathrm{b}}$, Danique Hellebrekers ${ }^{\mathrm{a}}$, Esther Kruitwagen-van \\ Reenen $^{\mathrm{c}}$ and Johanna Visser-Meily ${ }^{\mathrm{c}, *}$ \\ ${ }^{\text {a }}$ School for Mental Health and Neuroscience, Maastricht University Medical Center, Maastricht, The Netherlands \\ ${ }^{\mathrm{b}}$ Merem Rehabilitation Center De Trappenberg, Almere, The Netherlands \\ ${ }^{\mathrm{c} C e n t e r}$ of Excellence in Rehabilitation Medicine, Brain Center Rudolf Magnus, University Medical Center \\ Utrecht, and De Hoogstraat Rehabilitation, Utrecht, The Netherlands \\ ${ }^{\mathrm{d}}$ Department of Neuropsychology and Psychopharmacology, Maastricht University, Maastricht, The Netherlands
}

\begin{abstract}
.
Background: Myotonic Dystrophy type 1 (DM1) is primarily a neuromuscular disease but can also have neuropsychological consequences (i.e.cognitive, emotional and behavioural) which can influence daily living and societal participation. Not much is known about the level of participation of DM1 patients and their relatives and the factors influencing participation. This information can guide the development of rehabilitation programs and identify those at risk of long-term participation problems.

Objective: To investigate the level of participation of DM1 patients and their partners and the determinants.

Methods: Cross-sectional study using the Utrecht Scale for Evaluation of Rehabilitation-Participation. Determinants were demographic, disease related, and neuropsychological characteristics. Spearman correlations and backward multiple regression analyses were performed.

Results: Of the 66 DM1 participants, 54\% reported severe fatigue and 47\% apathy. Experienced participation restrictions were most prevalent in housekeeping (74\%), sports (68\%) and outdoor activities $(55 \%)$. Participants were relatively satisfied with their level of participation, but dissatisfaction occurred mostly in housekeeping (58\%), outdoor activities (55\%), and sports $(54 \%)$. Age and apathy were significant predictors of frequency of $\left(\mathrm{R}^{2}=10.4\right)$ and restrictions in participation in the multivariate model $\left(\mathrm{R}^{2}=14.4\right)$. Emotional functioning was the only significant predictor of satisfaction with participation $\left(\mathrm{R}^{2}=23.8\right)$.

Conclusions: A considerable number of DM1 patients have Central Nervous System-related problems such as fatigue and apathy in addition to neuromuscular restrictions. Risk factors for lower participation are age, apathy, and emotional problems. Physical as well as neuropsychological rehabilitation programs are recommended.
\end{abstract}

Keywords: Activities of daily living, social participation, myotonic dystrophy, neuromuscular diseases, apathy

\footnotetext{
*Correspondence to: Anne Visser-Meily, Center of Excellence for Rehabilitation Medicine, University Medical Center Utrecht and De Hoogstraat Rehabilitation, Utrecht, W01 121, P.O. Box 85500, 3508 GA Utrecht, The Netherlands. Tel.: +31 887558831 ; Fax: +31 8875554 50. E-mail: j.ma.visser-meily@ umcutrecht.nl.
}

\section{INTRODUCTION}

Myotonic Dystrophy type 1 (DM1) is a slowly progressive neuromuscular disease with an autosomal dominant transmission. It is the most common neuromuscular disease in adults, with a global incidence of 1 in 8000 individuals [1, 2]. DM1 is characterized 
primarily by myotonia and progressive muscle weakness, but also affects the ocular, cardiac, respiratory, gastrointestinal and the central nervous system, which essentially means this is a multi-systemic disorder. Involvement of the central nervous system (CNS) may lead to neuropsychological consequences such as cognitive, emotional and behavioral deficits.

In adult-onset DM1 involvement of the CNS is associated with hypersomnia and fatigue, as well as visuoconstructive impairment, attention deficits, reduced initiative and apathy [3]. Impairments in executive functioning (i.e. initiative, planning, organization and flexibility) are especially prominent suggesting the involvement of the frontal lobes [4]. Some characteristics of the cognitive deficits in DM1 patients are related to specific structural cerebral changes [5]. In the course of five years, cognitive decline is also seen in adult DM1 patients which is related to earlier onset and longer duration of the disease [6]. A recent study in which a nine year follow up was conducted suggests an earlier and more accelerated normal cognitive aging process in DM 1 patients [7]. The presence of depression can also reflect the involvement of the CNS, but some authors have suggested that depressed mood reflects an emotional reactive adjustment disorder rather than structural brain damage [8]. The high prevalence of other CNS- related symptoms such as apathy (almost 40\%), suggests a central cause rather than an adjustment process [9].

These neuropsychological consequences can have a negative influence on the patients' daily living, participation in society, and quality of life. A recent study found that both physical and mental health related quality of life (HRQOL) were impaired in DM1 patients [10]. Many different factors including demographic, disease-related and neurological factors contribute to this reduced level of HRQOL. In another study [11] only physical HRQOL was reduced which was not only related to disease related characteristics such as daytime sleepiness and fatigue, but also to psychological distress, unemployment, and dissatisfaction with social participation. More recently, a study [12] showed that cognitive deficits and fatigue both negatively impact the quality of life of juvenile and adult DM1 patients. No study, however, has investigated the contribution of the neuropsychological related to brain involvement to the level of participation in society. From a clinical perspective, it is important to establish whether any factors that would be responsive to treatment, contribute to reduced daily functioning, as that would mean that not only physical, but also neuropsychological rehabilitation programs could be effective in this patient group.

The need for assistance has been found to influence the well-being of patients more than the symptoms of the disease [13], and this may also impact caregiver burden and partner well-being. Patients' lack of initiative and avoidant behavior also influences the well-being of their partners [13, 14]. This suggests that rehabilitation programs should involve psychosocial interventions for both patients and partners. However, as there is only one quantitative study in which both patients and partners were investigated, further evidence is needed.

The primary aim of the present study was therefore to describe the level of participation of patients with DM1 and of their caregivers. The second aim was to determine whether demographic, disease-related and neuropsychological characteristics were related to participation of the patients and finally, which of these factors were related to caregiver functioning (i.e. burden and emotional functioning).

\section{METHODS}

\section{Participants}

Patients who visited the DM outpatient clinic at the University Medical Centre Utrecht, the rehabilitation centers Revant in Breda, Het Roessingh in Enschede and VieCuri in Venlo (the Netherlands) from March 2011 to October 2012 were eligible for participation in the study. Inclusion criteria were a diagnosis of the classic form of DM1, as confirmed by a neurologist, over 18 years of age, and living independently. If a caregiver was present, they were also asked to participate. Partners were included if they were married or living together with the patient. If the patient did not have a partner, a relative, who knew the patient well, such as a parent, sibling or adult child was asked to participate.

\section{Procedure}

Patients and caregivers were recruited during a regular outpatient visit to one of the participating centers. Their rehabilitation physician and/or specialized DM nurse informed the patient and caregiver about the study, both orally and in writing. Patients and their partners/caregivers were asked to complete one set of questionnaires (see Measures) and gave permission to use data from their medical 
file. The rehabilitation physician who performed a physical examination filled in the Muscular Impairment Rating Scale (MIRS). All other variables were collected via the questionnaires. Participants either completed the questionnaires during their outpatient visit, or took them home and returned them using the freepost envelope provided. The study was conducted in accordance with guidelines on human experimentation and approved by the Medical Ethics Committee of the UMC Utrecht and the rehabilitation centers which is in accord with the Helsinki Declaration of 1975. All patients and caregivers provided a signed consent form at the start of the study.

\section{Measures}

\section{Outcome: Participation}

Participation was measured using the Utrecht Scale for Evaluation of Rehabilitation-Participation (USER-P) [15]. The USER-P is a self-report measure, consisting of three participation domains (frequency, restrictions, satisfaction), with a total of 32 items. The following domains of participation are measured: vocational activities (i.e. work, education and housekeeping) and leisure and social activities (i.e. of sports and physical exercise, going out, making day trips, leisure activities at home, visiting family or friends, receiving visits from family or friends, and contacts by computer or telephone). The sum score of each domain ranges from 0 to 100 . The higher the sum score, the better the level of participation (higher frequency, fewer restrictions, higher satisfaction). To quantify the presence of restrictions and dissatisfaction in different domains of participation, the item scores of the USER-Participation Restriction and Satisfaction scales were dichotomized. The Restriction scale, 'with assistance', 'with difficulty', and 'not possible' were defined as 'restriction', and 'without difficulty' and 'not applicable' were defined as 'no restriction'. For the Satisfaction scale, 'very dissatisfied', 'dissatisfied', and 'neutral' were defined as 'dissatisfaction', and 'satisfied' and 'very satisfied' were defined as 'satisfaction'. The USER$P$ has previously shown satisfactory validity and reliability [15].

\section{Determinants}

\section{Demographic characteristics}

The level of education was recorded using the Dutch classification system ranging from 1 (did not finish primary school) to 7 (university education), which was dichotomized as low (0-5) and high (6-7). Marital status was identified using five categories: 'married/living together, 'single', 'divorced', 'widow/widower' and 'otherwise'. Employment status was measured by using a closed question: "Are you currently in paid employment and for how many hours?"

\section{Disease characteristics}

Age-of-onset of DM1 was taken from the medical case notes. Muscle strength was assessed by a rehabilitation physician using the Muscular Impairment Rating Scale (MIRS), a 5-point scale focusses on proximal muscle weakness where 1 is no muscular impairment, 2 minimal signs, 3 weaknesses present (with or without weakness of the elbow extensors), 4 mild-to-moderate weaknesses and 5 severe proximal weaknesses [16]. Mild muscular impairment was defined as MIRS grades 1-3 and severe muscular impairment as MIRS grades 4-5. Studies in persons with DM support the validity and reliability of the scale [16].

Daytime sleepiness was measured using the Epworth Sleepiness Scale (ESS), an 8-item questionnaire, which asks about daytime sleepiness over the previous 4 weeks. Each item is rated on a scale of $0-3$, leading to a total score range of 0-24. A score above 10 indicates the presence of excessive daytime sleepiness [16], and is considered to be sufficiently reliable $[17,18]$.

Fatigue was measured using the Fatigue Severity Scale (FSS) [19], a 9-item questionnaire, asking about fatigue over the previous 7 days. Each item is rated on a Likert scale ranging from 1 (strongly disagree) to 7 (strongly agree). A higher total score represents higher levels of fatigue. A score equal to or above 4 indicates a moderate to high impact of fatigue on daily living. The scale has a high reliability [19].

\section{Neuropsychological characteristics}

Subjective cognitive functioning was measured by the Cognitive Failure Questionnaire (CFQ). This questionnaire contains 25 items about the frequency of everyday cognitive failure. Scores range between $0-100$, with higher scores indicating more problems with cognitive functioning [20]. A score higher than 43.5 indicates the presence of cognitive failures.

The Apathy Evaluation Scale (AES) was used to assess the presence of apathy or the lack of initiative. This is an 18-item scale, scored from 1 (not at all characteristic) to 4 (very characteristic), with total scores 
ranging from 18 to 72 , higher scores indicating more apathy. A score of 34 or higher indicates a clinically relevant level of apathy [21].

Anxiety and depression were evaluated in both patients and spouses using the Dutch Hospital Anxiety and Depression Scale (HADS) [22] which is a 14-item questionnaire divided into two separate scales. Each subscale contains seven items asking about the person's feelings over the last week. Each question is rated from 0 (no symptoms) to 4 (maximum distress). The total score ranges from 0 to 56 , and 0 to 28 for each subscale. A subscale score above 8 indicates the presence of a probable clinically relevant level of depression or anxiety.

Patients rated their own cognitive complaints (CFQ), apathy (AES) and emotional functioning (HADS). Caregivers reported on the cognitive complaints (CFQ) and apathy (AES) of the patient and on their own emotional functioning (HADS).

\section{Caregiver burden}

Caregiver burden was measured using the Caregiver Strain Index (CSI) [23]. The CSI is a 13-item questionnaire of closed questions with a score range from $0-13$, completed by the spouse. Seven or more positive answers indicate a high burden level.

\section{Statistical analyses}

IBM SPSS Statistics version 22 was used for statistical analysis. Descriptive statistics were used to describe the sample in terms of demographic characteristics, disease and neuropsychological characteristics. Continuous data were checked for normality.

Bivariate correlations between the demographic, disease and neuropsychological determinants and USER-P patient, HADS-patient, HADS-partner and Caregiver Strain Index scores were tested using Spearman correlations. Because the present study was exploratory, backward multiple regression analyses were chosen to examine associations between the determinants and USER-P as primary outcome measure for the patients. Similar analyses were performed to investigate determinants of caregiver burden (CSI) and emotional functioning (HADS-partner). In the first step the significant variables from the bivariate correlational analyses were entered; in the final step the significant predictors were retained in the regression model. A p-level of $<0.05$ was used to indicate statistical significance.

\section{RESULTS}

\section{Patient and partner characteristics}

From March 2011 to October 2012, 87 patients with DM1 were invited to visit the participating outpatient clinics. Twenty-one patients were excluded: eight did not respond or declined participation, six were living in a nursing home and thus did not live independently (inclusion criterion), six were treated outside the area in another center, and one had died. Sixty-six patients were included in this study. Fiftyfive caregivers of patients returned the questionnaire, 32 partners and 23 relatives. The characteristics of these participants are displayed in Table 1 .

About half of patients $(54.5 \%)$ and half of their partners $(50 \%)$ were men, and about $60 \%$ of patients were married or living together. The mean age of the patients was 47 (12.7). The partners and relatives were somewhat older $(\mathrm{M}=51.2, \mathrm{SD}=10,5)$. Nearly $70 \%$ of both patients and partners were categorized as having 'low level education', and 60\% of the patients did not have a paid job.

Eighty-seven percent of the patients showed minimal signs of paresis as measured by the MIRS scale. More than half of the patients scored above the cutoff point of the FSS, indicating severe fatigue. About one third of the patients (29\%) scored above the cutoff point of the ESS, indicating clinically relevant daytime sleepiness.

Thirteen percent of the patients had problems in cognitive functioning on the CFQ and almost half of the patients had a clinically relevant level of apathy (AES). Subjective cognitive complaints of patients perceived by caregivers were lower than those experienced by patients themselves $(\mathrm{M}=30 \mathrm{SD}=13$ versus Partners $M=28,6, S D=13,2$ and Relatives $M=31$, $\mathrm{SD}=10.8)$. Caregivers also rated the presence of apathy as frequently occurring (44-48\%). HADS scores showed that one in five patients and partners had depressive symptoms (18.2\% and $21.9 \%$, respectively), and more than a third had high anxiety levels (30.8\% and $37.5 \%$, respectively). Only a minority of the partners $(15.6 \%)$ experienced high caregiver burden.

\section{Participation (USER-Participation)}

The mean Frequency score was 31.0 (SD 11.8) for patients and 39.6 (SD 8.0) for partners. The mean Restriction score was 73.3 (SD 19.9) for patients and 91.8 (SD 12.5) for partners. Most restric- 
Table 1

Characteristics of patients with Myotonic Dystrophy type 1 and their partners or relatives

\begin{tabular}{|c|c|c|c|}
\hline & Patients $(n=66)$ & Partners $(n=32)$ & Relatives $(n=23)^{\mathrm{a}}$ \\
\hline \multicolumn{4}{|l|}{ Demographic characteristics } \\
\hline Gender, male n $(\%)$ & $36(54.5)$ & $16(50)$ & $5(22)$ \\
\hline Mean age in years (SD) & $47(12.7)$ & $51.2(10.5)$ & $52.8(17.5)$ \\
\hline \multicolumn{4}{|l|}{ Marital status (\%) } \\
\hline Married/living together & 61.5 & 100 & \\
\hline Living alone & 18.5 & & \\
\hline Other & 20 & & \\
\hline Educational level at least high school (n, \%) & 26.6 & 37.5 & 26.1 \\
\hline \multicolumn{4}{|l|}{ Employment status (\%) } \\
\hline Full time paid employment & 13.8 & - & - \\
\hline Part time paid employment & 26.2 & & \\
\hline No paid job & 60 & - & - \\
\hline \multicolumn{4}{|l|}{ Disease characteristics patient } \\
\hline Mean illness duration in years (SD) & $21(10.8)$ & $\mathrm{n} / \mathrm{a}-$ & $\mathrm{n} / \mathrm{a}-$ \\
\hline \multicolumn{4}{|l|}{ Muscular Impairment Rating Scale $(n=47)$} \\
\hline Mild paresis, $1-3(\%)$ & 87.2 & & \\
\hline Severe paresis, $4-5(\%)$ & 12.8 & & \\
\hline \multicolumn{4}{|l|}{ Fatigue severity scale $(n=59)$} \\
\hline Mean (SD) & $3.9(1.3)$ & & \\
\hline Fatigue score $>4(\%)$ & 54.2 & & \\
\hline \multicolumn{4}{|l|}{ Epworth Sleeping Scale $(n=50)$} \\
\hline Mean (SD) & $8.1(4.3)$ & & \\
\hline Excessive daytime sleepiness score $>10(\%)$ & 28.8 & & \\
\hline \multicolumn{4}{|l|}{ Neuropsychological characteristics } \\
\hline Cognitive complaints, CFQ (n) & 61 & 29 & 21 \\
\hline Mean (SD) & $30(13)$ & $28.6(13.2)^{\mathrm{b}}$ & $31(10.8)^{\mathrm{b}}$ \\
\hline Cognitive failures score $>43.5(\%)$ & 13.1 & 9.4 & 8.7 \\
\hline Behavioral complaints AES (n) & 58 & 29 & 22 \\
\hline Mean (SD) & $34.2(7.8)$ & $35(10.8)^{\mathrm{b}}$ & $36.4(9.9)^{\mathrm{b}}$ \\
\hline Apathy score >34 (\%) & 46.6 & 43.8 & 47.8 \\
\hline Emotional complaints ${ }^{\mathrm{c}}$, HADS (n) & 65 & 31 & \\
\hline Mean Anxiety (SD) & $5.6(3.2)$ & $6.5(2.8)$ & \\
\hline Anxiety subscore $>7(\%)$ & 30.8 & 37.5 & \\
\hline Mean Depression (SD) & $4.6(3.3)$ & $5.0(3.4)$ & \\
\hline Depression subscore $>7(\%)$ & 18.2 & 21.9 & \\
\hline \multicolumn{4}{|l|}{ Caregiver functioning } \\
\hline \multicolumn{4}{|l|}{ Caregiver burden, CSI } \\
\hline Mean (SD) & & $4.2(3.2)$ & \\
\hline High burden score $>6(\%)$ & & 15.6 & \\
\hline
\end{tabular}

${ }^{a}$ Relatives were defined as brother, sister, parent, child, friend or mentor. ${ }^{b}$ Partner or relatives scores for patient. ${ }^{c}$ Patient and partner scores for themselves. MIRS = Muscular Impairment Rating Scale; FSS = Fatigue Severity Scale; ESS = Epworth Sleepiness Scale; CFQ = Cognitive Failure Questionnaire; AES = Apathy Evaluation Scale, $\mathrm{CSI}=$ Caregiver Strain Index, HADS $=$ Hospital Anxiety and Depression Scale.

tions were experienced by patients in housekeeping (74.2\%), sports/leisure activities (67.7\%) and activities outside the home environment (54.5\%).For partners restrictions were most often experienced in the relationship with their partner (45.2\%). The percentages of patients and partners experiencing restrictions and dissatisfaction are shown in Table 2.

The mean Satisfaction score was 64.5 (SD 13.3) for patients and 71.8 (SD 12.5) for partners.

Patients were least satisfied with housekeeping $(57.8 \%)$, sports/leisure activities $(54.0 \%)$ and activities outside the home environment (65.0\%). Partners were least satisfied with going out (46.0\%) and day trips and other outdoor activities (46.0\%).

\section{Determinants of patient participation}

Table 3 shows the bivariate relationships between the demographic, disease, and neuropsychological characteristics and the subscales of the USERP. Age and AES scores were significantly and negatively correlated with frequency of participation in social activities (USER-P frequency). Age, ESS, FSS, AES, and HADS correlated significantly with USER-P Restrictions and FSS, AES and 
Table 2

Participation - restrictions and satisfaction

\begin{tabular}{|c|c|c|c|c|}
\hline \multirow[t]{2}{*}{ USER-P items } & \multicolumn{2}{|c|}{$\begin{array}{c}\text { Patient } \\
(n=66)^{*}\end{array}$} & \multicolumn{2}{|c|}{$\begin{array}{c}\text { Partner } \\
(n=32)^{*}\end{array}$} \\
\hline & $\mathrm{N}$ & $\%$ & $\overline{\mathrm{N}}$ & $\%$ \\
\hline \multicolumn{5}{|l|}{$\%$ patients/partners experiencing restrictions } \\
\hline Paid job, voluntary work or education & 65 & 47.7 & 31 & 9.7 \\
\hline Housekeeping & & 74.2 & & 21.9 \\
\hline Outdoor mobility & & 45.5 & & 9.4 \\
\hline Sports/physical activities & 65 & 67.7 & & 21.9 \\
\hline Going out & 63 & 39.7 & & 21.9 \\
\hline Day trips and other outdoor activities & & 54.5 & & 28.1 \\
\hline Leisure activities at home & & 16.7 & & 18.8 \\
\hline Relationship with partner & 65 & 24.6 & & 45.2 \\
\hline Visiting family and friends & 65 & 29.2 & & 21.9 \\
\hline Receive visitors at home & & 15.2 & & 12.5 \\
\hline Contacting people by telephone or computer & & 10.6 & & 6.3 \\
\hline \multicolumn{5}{|l|}{$\%$ patients/partners unsatisfied } \\
\hline Paid job, voluntary work or education & 37 & 19.7 & 29 & 15.6 \\
\hline Housekeeping & 64 & $\mathbf{5 7 . 8}$ & & 34.4 \\
\hline Outdoor mobility & 65 & 35.4 & & 6.3 \\
\hline Sports/physical activities & 63 & 54.0 & & 28.1 \\
\hline Going out & 63 & 52.4 & & 40.6 \\
\hline Day trips and other outdoor activities & 62 & 54.0 & & 40.6 \\
\hline Leisure activities at home & & 18.2 & & 18.8 \\
\hline Relationship with partner & 45 & 13.6 & & 21.9 \\
\hline Relationship with family & & 13.6 & & 15.6 \\
\hline Contact with friends and acquaintances & 65 & 26.2 & & 21.9 \\
\hline
\end{tabular}

*unless otherwise specified. Bold \% numbers indicate: restrictions $>50 \%$ or unsatisfied $>50 \%$. USER-P $=$ Utrecht Scale for Evaluation of Rehabilitation-Participation.

Table 3

Bivariate analyses of patient characteristics and patients' USER-Participation subscale scores and patient mood

\begin{tabular}{lccccc}
\hline Determinant & $\mathrm{N}$ & $\begin{array}{c}\text { USER-P } \\
\text { Frequency }\end{array}$ & $\begin{array}{c}\text { USER-P } \\
\text { Restrictions }\end{array}$ & $\begin{array}{c}\text { USER-P } \\
\text { satisfaction }\end{array}$ & $\begin{array}{c}\text { HADS } \\
\text { patient }\end{array}$ \\
\hline Demographic characteristics & & & & & \\
$\quad$ Age & 66 & $-0.391^{* *}$ & $-0.544^{* *}$ & -0.209 & 0.208 \\
$\quad$ Gender & 66 & -0.009 & 0.154 & 0.034 & 0.125 \\
$\quad$ Marital status & 65 & -0.104 & -0.038 & -0.051 & -0.035 \\
$\quad$ Education & 64 & 0.163 & -0.021 & -0.067 & -0.233 \\
Disease characteristics & & & & & \\
$\quad$ MIRS & 47 & -0.260 & -0.243 & -0.235 & 0.146 \\
ESS & 59 & 0.107 & 0.274 & 0.159 & 0.143 \\
$\quad$ FSS & 59 & -0.223 & $-0.336^{* *}$ & $-0.391^{* *}$ & $0.429^{* *}$ \\
Neuropsychological characteristics & & & & & \\
$\quad$ CFQ & 61 & -0.047 & -0.121 & -0.210 & $0.486^{* *}$ \\
AES & 58 & $-0.332^{* *}$ & $-0.329^{*}$ & $-0.275^{*}$ & $0.447^{* *}$ \\
HADS & 65 & -0.242 & $-0.287^{*}$ & $-0.511^{* *}$ & - \\
\hline
\end{tabular}

NOTE: Correlation coefficient is Spearman's rho. ${ }^{* *}$ Correlation is significant at the 0.01 level (2-tailed). *Correlation is significant at the 0.05 level (2-tailed). Frequency, participation and satisfaction with participation are subscales of the Utrecht Scale for Evaluation of Rehabilitation-Participation. Higher scores on the subscales indicate good levels of participation (higher frequency, less restrictions, higher satisfaction). MIRS = Muscular Impairment Rating Scale, ESS = Epworth Sleepiness Scale, FSS = Fatigue Severity Scale, AES = Apathy Evaluation Scale; HADS $=$ Hospital Anxiety and Depression Scale.

HADS showed significant relationships to USER-P Satisfaction.

Multivariate linear regression analyses showed that age and AES were significantly associated with USER-P frequency and with USER-P restrictions in the final regression model, explaining $10.4 \%$ and $14.4 \%$ of the total variance. In the multivariate analysis with the USER-P satisfaction HADS was the only significant predictor in the final model, explaining $23.8 \%$ of the total variance (see Table 4 ). 
Table 4

Results of the multivariate linear regression analyses with USER-P as outcome and its determinants

\begin{tabular}{lccc}
\hline Determinants & USER-P & USER-P & USER-P \\
& Frequency $\beta$ & Restrictions $\beta$ & Satisfaction B \\
\hline Age & $-0.34^{*}$ & $-0.53^{*}$ & \\
AES & $-0.40^{*}$ & $-0.31^{*}$ & $-0.57^{*}$ \\
HADS & & & $23.8 \%$ \\
Explained variance & $10.4 \%$ & $14.4 \%$ & \\
\hline
\end{tabular}

USER-P = Utrecht Scale for Evaluation of Rehabilitation-Participation; AES = Apathy Evaluation Scale; HADS $=$ Hospital Anxiety and Depression Scale. ${ }^{*}=p<0.05$.

\section{Determinants of partners' burden and emotional functioning}

Table 5 shows the correlations between patient and partner characteristics, and partners' caregiver burden (CSI) and emotional functioning (HADSpartner). The level of restrictions as experienced by the patient was significantly and negatively correlated with caregiver burden. Partner mood was significantly and positively correlated with caregiver burden, indicating that those partners with more symptoms of depression or anxiety experienced higher caregiver burden. There were no significant

Table 5

Bivariate correlations of patient and partner characteristics, and CSI and HADS of the partner

\begin{tabular}{lccc}
\hline Determinant & $\mathrm{N}$ & $\mathrm{CSI}$ & HADS partner \\
\hline Patient & & & \\
Demographic characteristics & & & \\
$\quad$ Age & 32 & 0.026 & 0.71 \\
$\quad$ Gender & 32 & 0.079 & -0.087 \\
$\quad$ Education & 21 & -0.113 & -0.311 \\
Disease characteristics & 22 & 0.105 & 0.150 \\
$\quad$ MIRS & 29 & 0.139 & -0.061 \\
$\quad$ ESS & 30 & 0.224 & -0.075 \\
$\quad$ FSS & & & \\
Neuropsychological charactistics & 29 & 0.182 & 0.257 \\
$\quad$ CFQ & 28 & 0.252 & 0.219 \\
$\quad$ AES & 32 & 0.045 & 0.185 \\
$\quad$ HADS & 32 & $-\mathbf{0 . 3 8 8}$ & -0.203 \\
Participation restrictions & & & \\
$\quad$ USER-P & & & \\
Partner & 32 & -0.032 & 0.088 \\
Demographic characteristics & 32 & -0.174 & -0.022 \\
$\quad$ Age & & & \\
$\quad$ Gender & 31 & $\mathbf{0 . 5 6 3}^{* *}$ & - \\
Psychosocial characteristics & & \\
$\quad$ HADS &
\end{tabular}

NOTE: Correlation coefficient is Spearman's rho. ${ }^{* *}$ Correlation is significant at the 0.01 level (2-tailed). ${ }^{*}$ Correlation is significant at the 0.05 level (2-tailed). MIRS = Muscular Impairment Rating Scale, ESS = Epworth Sleepiness Scale, FSS = Fatigue Severity Scale, HADS = Hospital Anxiety and Depression Scale, $\mathrm{CFQ}=$ Cognitive Failure Questionnaire; $\mathrm{AES}=$ Apathy Evaluation Scale; CSI $=$ Caregiver Strain Index, USER-P = Utrecht Scale for Evaluation of Rehabilitation-Participation. correlations between any of the patient and partner characteristics and the HADS-partner.

\section{DISCUSSION}

DM1 is a multi-systemic disorder in which the neuromuscular problems are most prominent, but the present study shows that CNS-related symptoms such as apathy, depression and anxiety are involved in the disease process as well. Half of all patients reported fatigue and apathy, although the majority $(87.2 \%)$ had only mild paresis. In addition, one-third experienced anxiety, and some (respectively $30 \%$ and $18.2 \%$ ) also had cognitive and depressive complaints. These CNSrelated symptoms can lead to restrictions in many areas of daily functioning such as work, housekeeping, sports and leisure activities and other activities outside the home environment. Partners experienced most restrictions in their relationship with their partner with DM1. Age and apathy were associated with frequency of and restrictions in participation, but did not explain much variance in the model. Emotional functioning was associated with satisfaction in participation, explaining a quarter of the variance. The restrictions in participation of the patient and the level of emotional functioning of the partner were associated with caregiver burden. Caregiver well-being has been shown to be influenced by patient characteristics before [13, 14].

Gagnon et al. [24] also showed disrupted participation in DM1 patients as measured with the Life Habits Measure ( $n=200,121$ women). Disrupted participation was defined as the amount of help needed to perform most life habits. Fourty-five to $61 \%$ of the patients showed disrupted participation in all four domains being mobility, housing, employment and recreation, similar to the domains of the USER-P. Fatigue, strength, family support and public services were independent predictors. Similar to our results, predictors of participation are both personal and environmental factors. The level of participation of DM1 patients is lower than that of their partners, 
but comparable to other patients who have received rehabilitation [15]. The frequency of and satisfaction with participation is lower than in patients with spinal cord injury [2]. The neuropsychological problems in DM1 patients may cause this difference. The experienced restrictions by DM1 patients in this study are higher than those experienced by stroke patients 6 months after their stroke and being discharged home from hospital [26]. These findings, combined with the contribution of neuropsychological characteristics to the level of participation, suggest that central neural mechanisms may play an important role in addition to neuromuscular mechanisms in DMI.

Moreover, the disease characteristics (i.e. motor functioning, sleep and fatigue) did not contribute significantly to the level of participation. In their recent review Gourdon and Meola [27] also state that central nervous system alterations are a common element of this multisystemic disease thereby recognizing myotonic dystrophies as brain diseases.

Involvement of the central nervous system is further strengthened by the finding that many DM1 patients report levels of fatigue comparable to levels of fatigue experienced by stroke patients [28]. The percentage of DM1 patients reporting apathy $(47 \%)$ is much higher than in the stroke population during the first year post stroke (27\%) [29]. Depressive symptoms occur somewhat less than in stroke patients two months post stroke [30], and feelings of anxiety are higher [31]. Subjective cognitive complaints were, however, not experienced often and the mean score on the CFQ was lower than in stroke patients and comparable to controls [32]. From clinical experience we know that DM type 1 patients do not experience many problems subjectively despite the level of objective functioning. This could also be one of the reasons why they often do not comply to motor exercises. A discrepancy is seen between self-awareness of motor functioning and objective measurements. This may also explain the low level of cognitive complaints.

Although most chronic diseases are accompanied by fatigue, depressive symptoms and anxiety, the presence of cognitive consequences and apathy in DM1 suggest additional involvement of the central nervous system. However, the relationships between these factors were not examined in our study but should also be considered in order to understand the underlying mechanisms and causality. Fatigue and sleep dysfunction, for instance, may lead to cognitive problems and depressive symptoms without specific brain involvement in the disease process.
This study presents some unique data that adds to our understanding of DM1 as a multisystemic disease, but it does have some limitations. In comparison to the study of Gagnon et al. [24] $(n=200)$ we have a limited sample size. The cross-sectional design of the study does not permit statements about causal relationships. Future studies should explore the longitudinal relationship between the developments of apathy, fatigue, mood disorders and the level of participation. We only included one type of DM and the sample showed variation in illness duration. Additionally, we measured sleepiness with the Epworth Sleepiness scale while recently it was shown that the Fatigue and Daytime Sleepiness Scale (FDSS) is more reliable in this patient group [33]. We measured cognitive functioning only in terms of subjective cognitive functioning and did not perform objective cognitive testing nor did we measure the level of awareness of the patients. The subjective nature of complaints may have influenced the experience of participation. Objective cognitive testing and measures of awareness should be considered in future studies. Finally, the group of relatives was rather heterogeneous involving brothers, sisters, parents and adult children who could be living with patient or not, which may have caused bias in the scores on the questionnaires in this subgroup. However, we also studied partners as a separate homogeneous group allowing stronger conclusions.

A considerable proportion (47\%) of our sample experienced clinically significant apathy, as indicated as a score of 34 or higher on the AES. Given that patients may have declined to participate because of high levels of apathy, the high prevalence of apathy in this sample may be an underestimate of levels of apathy in patients with DM1. Further large scale prospective studies are necessary to confirm these findings.

The results of this study suggest that rehabilitation programs for DM1 should not solely focus on the more obvious neuromuscular symptoms, but attention may also need to be paid to any neuropsychological symptoms. Information on the brain-related aspects of the disease may be offered to both patients and their caregivers; as this may help reduce emotional problems in patients and partners/caregivers. Future studies should assess whether rehabilitation for neuropsychological symptoms is beneficial in patients with DM1. Currently an RCT is being conducted in which cognitive behavioural therapy is combined with graded exercises and compared to standard care for DM 1 patients, but results have not 
been reported yet [34]. Recently a study on childhood phenotype of MD 1 patients showed that participation restrictions were present and related to problems in many different areas of functioning [35]. The authors also recommend an interdisciplinary approach. In two other studies by the same research group an integrated care program involving health, social and community services is recommended based on the correlates of health-related quality of life in DM 1 patients [36]; a more holistic approach is needed in which all relevant stakeholders are involved [37]. Other medical conditions in which a mere physical rehabilitation approach has successfully been augmented with psychological interventions is in the field of cardiac rehabilitation where stress, anxiety and depression play a major role in the outcome of treatment [38].

Although not a determinant, $50 \%$ of the patients report fatigue. The occupational therapists could help the patients increase their level of participation and manage their daily routines by applying energy management principles to reduce fatigue. Further, we suggest the high prevalence of clinically relevant apathy in these patients may require a proactive role of the rehabilitation professional. Specific rehabilitation interventions can be developed on the basis of these findings.

From the present study we can conclude that DM1 is a complex disease that affects not only physical functioning but many domains of cognitive functioning and mood in patients, and may also affect caregivers' mood and experienced burden of caregiving. Risk factors for lower participation identified in this study were age, apathy and emotional problems. Targeted rehabilitation programmes should be considered.

\section{ACKNOWLEDGMENTS}

No financial or material support was received for the study in this paper.

We would like to thank all participating rehabilitation centers and hospitals: University Medical Center Utrecht, Revant Rehabilitation (Breda), Het Roessingh Rehabilitation (Enschede), Vie Curi Rehabilitation (Venlo). In particular, we would like to thank J.W. Meijer, R. van Vliet and W.Wetzelaer. We would like to thank R. de Gooijer for participating and C. Vrinten for providing useful comments on an earlier draft of the manuscript.

\section{CONFLICT OF INTEREST STATEMENT}

None of the authors report any conflicts of interest.

\section{REFERENCES}

[1] Bouhour F, Bost M, Vial C. Steinert disease. Presse Med. 2007;36(6 Pt 2):965-71.

[2] Harper P. Myotonic dystrophy. Oxford University Press, 2007.

[3] Meola G, Sansone V. Cerebral involvement in myotonic dystrophies. Muscle Nerve. 2007;36(3):294-306.

[4] Meola G, Sansone V, Perani D, Scarone S, Cappa S, Dragoni C, Cattaneo E, Cotelli M, Gobbo C, Fazio F, Siciliano G, Mancuso M, Vitelli E, Zhang S, Krahe R, Moxley RT. Executive dysfunction and avoidant personality trait in myotonic dystrophy type 1 (DM-1) and in proximal myotonic myopathy (PROMM/DM-2). Neuromuscul Disord. 2003;13(10):813-21.

[5] Weber YG, Roebling R, Kassubek J, Hoffmann S, Rosenbohm A, Wolf M, Steinbach P, Jurkat-Rott K, Walter H, Reske SN, Lehmann-Horn F, Mottaghy FM, Lerche H. Comparative analysis of brain structure, metabolism, and cognition in myotonic dystrophy 1 and 2. Neurology. 2010;74(14):1108-17.

[6] Winblad S, Samuelsson L, Lindberg C, Meola G. Cognition in myotonic dystrophy type 1: A 5-year follow-up study. Eur J Neurol. 2016;23(9):1471-6.

[7] Gallais B, Gagnon C, Mathieu J, Richer L. Cognitive decline over time in adults with myotonic dystrophy type 1: A 9-year longitudinal study. Neuromuscul Disord. 2017;27(1):61-72.

[8] Minnerop M, Weber B, Schoene-Bake JC, Roeske S, Mirbach S, Anspach C, Schneider-Gold C, Betz RC, Helmstaedter C, Tittgemeyer M, Klockgether T, Kornblum C. The brain in myotonic dystrophy 1 and 2: Evidence for a predominant white matter disease. Brain. 2011;134(Pt 12):3530-46.

[9] Gallais B, Montreuil M, Gargiulo M, Eymard B, Gagnon C, Laberge L. Prevalence and correlates of apathy in myotonic dystrophy type 1. BMC Neurol. 2015;15:148.

[10] Peric S, Stojanovic VR, Basta I, Peric M, Milicev M, Pavlovic S, Lavrnic D. Influence of multisystemic affection on health-related quality of life in patients with myotonic dystrophy type 1. Clin Neurol Neurosurg. 2013;115(3):2705.

[11] Laberge L, Mathieu J, Auclair J, Gagnon É, Noreau L, Gagnon C. Clinical, psychosocial, and central correlates of quality of life in myotonic dystrophy type 1 patients. Eur Neurol. 2013;70(5-6):308-15.

[12] Rakocevic-Stojanovic V, Peric S, Madzarevic R, Dobricic V, Ralic V, Ilic V, Basta I, Nikolic A, Stefanova E. Significant impact of behavioral and cognitive impairment on quality of life in patients with myotonic dystrophy type 1 . Clin Neurol Neurosurg. 2014;126:76-81.

[13] Timman R, Tibben A, Wintzen AR. Myotonic dystrophy: The burden for patients and their partners. J Rehabil Med. 2010;42(9):823-30.

[14] Cup EH, Kinébanian A, Satink T, Pieterse AJ, Hendricks HT, Oostendorp RA, van der Wilt GJ, van Engelen BG. Living with myotonic dystrophy; what can be learned from couples? A qualitative study. BMC Neurol. 2011;11:86.

[15] Post MWM, van der Zee CH, Hennink J, Schafrat CG, Visser-Meily JMA, van Berlekom SB. Validity of the utrecht 
scale for evaluation of rehabilitation-participation. Disabil Rehabil. 2012;34:478-85.

[16] Mathieu J, Boivin H, Meunier D, Gaudreault M, Bégin P. Assessment of a disease-specific muscular impairment rating scale in myotonic dystrophy. Neurology. 2001;56;336-40.

[17] Johns MW. J Sensitivity and specificity of the multiple sleep latency test (MSLT), the maintenance of wakefulness test and the epworth sleepiness scale: Failure of the MSLT as a gold standard. Sleep Res. 2000;9(1):5-11.

[18] Laberge L, Gagnon C, Jean S, Mathieu J. Fatigue and daytime sleepiness rating scales in myotonic dystrophy: A study of reliability. J Neurol Neurosurg Psychiatry. 2005;76(10):1403-5.

[19] Krupp LB, LaRocca NG, Muir-Nash J, Steinberg AD. The fatigue severity scale. Application to patients with multiple sclerosis and systemic lupus erythematosus. Acta Neurologica, 1989;46(10):1121-3.

[20] Broadbent DE, Cooper PF, FitzGerald P, Parkes KR. The Cognitive Failures Questionnaire (CFQ) and its correlates. Br J Clin Psychol. 1982;21:1-16.

[21] Marin RS, Biedrzycki RC, Firinciogullari S. Reliability and validity of the Apathy Evaluation Scale. Psychiatry Res. 1991;38(2):143-62.

[22] Spinhoven Ph, Ormel J, Sloekers PPA, Kempen GIJM, Speckens AEM, Hemert van AM. A validation study of the Hospital Anxiety and Depression Scale (HADS) in different groups of Dutch subjects. Psych Med. 1997;27:363-70.

[23] Robinson BC. Validation of a caregiver strain index. J Gerontology. 1983;38:344-8.

[24] Gagnon C, Mathieu J, Jean S, Laberge L, Perron M, Veillette S, Richer L, Noreau L. Predictors of disrupted social participation in myotonic dystrophy type 1 . Arch Phys Med Rehabil. 2008;89(7):1246-55.

[25] Van der Zee CH, Post MW, Brinkhof MW, Wagenaar RC. Comparison of the utrecht scale for evaluation of rehabilitation-participation with the ICF measure of participation and activities screener and the WHO disability assessment schedule II in persons with spinal cord injury. Arch Phys Med Rehabil. 2014;95(1):87-93.

[26] Blömer AM, van Mierlo ML, Visser-Meily JM, van Heugten CM, Post MW. Does the frequency of participation change after stroke and is this change associated with the subjective experience of participation? Arch Phys Med Rehabil. 2015;96(3):456-63.

[27] Gourdon G, Meola G. Myotonic dystrophies: State of the art of new therapeutic developments for the CNS. Front Cell Neurosci. 2017;11:101.
[28] Schepers VP, Visser-Meily AM, Ketelaar M, Lindeman E. Poststroke fatigue: Course and its relation to personal and stroke-related factors. Arch Phys Med Rehabil. 2006;87(2):184-8.

[29] Angelelli P, Paolucci S, Bivona U, Piccardi L, Ciurli P, Cantagallo A, Antonucci G, Fasotti L, Di Santantonio A, Grasso MG, Pizzamiglio L. Development of neuropsychiatric symptoms in poststroke patients: A cross-sectional study. Acta Psychiatr Scand. 2004;110(1):55-63.

[30] van Mierlo ML, van Heugten CM, Post MW, de Kort PL, Visser-Meily JM. Psychological factors determine depressive symptomatology after stroke. Arch Phys Med Rehabil. 2015;96(6):1064-70.

[31] Kootker JA, van Mierlo ML, Hendriks JC, Sparidans J, Rasquin SM, de Kort PL, Visser-Meily JM, Geurts AC. Risk factors for symptoms of depression and anxiety one year poststroke: A longitudinal study. Arch Phys Med Rehabil. 2016;97(6):919-28.

[32] van Rijsbergen MW, Mark RE, de Kort PL, Sitskoorn MM. Prevalence and profile of poststroke subjective cognitive complaints. J Stroke Cerebrovasc Dis. 2015;24(8):1823-31.

[33] Gallais B, Gagnon C, Forgues G, Côté I, Laberge L· Further evidence for the reliability and validity of the Fatigue and Daytime Sleepiness Scale. J Neurol Sci. 2017;375:23-6.

[34] van Engelen B, OPTIMISTIC Consortium. Cognitive behaviour therapy plus aerobic exercise training to increase activity in patients with myotonic dystrophy type 1 (DM1) compared to usual care (OPTIMISTIC): Study protocol for randomised controlled trial. Trials. 2015;16:224.

[35] Gagnon C, Kierkegaard M, Blackburn C, Chrestian N, Lavoie M, Bouchard MF, Mathieu J. Participation restriction in childhood phenotype of myotonic dystrophy type 1: A systematic retrospective chart review. Dev Med Child Neurol. 2017;59(3):291-6.

[36] Laberge L, Mathieu J, Auclair J, Gagnon É, Noreau L, Gagnon C. Clinical, psychosocial, and central correlates of quality of life in myotonic dystrophy type 1 patients. Eur Neurol. 2013;70(5-6):308-15.

[37] Gagnon C, Chouinard MC, Laberge L, Veillette S, Bégin P, Breton R, Jean S, Brisson D, Gaudet D, Mathieu J, DMI Expert Panel. Health supervision and anticipatory guidance in adult myotonic dystrophy type 1 . Neuromuscul Disord. 2010;20(12):847-51.

[38] Chauvet-Gelinier JC, Bonin B. Stress, anxiety and depression in heart disease patients: A major challenge for cardiac rehabilitation. Ann Phys Rehabil Med. 2017;60(1):6-12. 